Tropical Journal of Pharmaceutical Research December 2010; 9 (6): 581-586

(C) Pharmacotherapy Group,

Faculty of Pharmacy, University of Benin,

Benin City, 300001 Nigeria.

All rights reserved.

Research Article

Available online at http://www.tjpr.org

\title{
Evaluation of Anticaries Activity of Selected Mouthwash Marketed in Nigeria
}

\section{BB Oluremi, MO Osungunna*, OA Idowu and OO Adebolu}

Department of Pharmaceutical Microbiology, Faculty of Pharmacy, Olabisi Onabanjo University, Sagamu, Nigeria

\begin{abstract}
Purpose: This work was aimed at evaluating four brands of mouthwash marketed in Nigeria for their anticaries activity.

Method: The susceptibility pattern of bacterial isolates obtained from 30 patients having carious teeth to the selected mouthwash was determined using the cup-plate method. The zones of inhibition produced by the mouthwash against the bacterial isolates were measured to determine the degree of susceptibility.

Results: The organisms isolated from the patients were Staphylococccus aureus, Klebsiella sp, Streptococcus sp, Escherichia coli and Pseudomonas aeruginosa in the following proportions: 30, 27, 20, 17 and $7 \%$, respectively. Anticaries evaluation revealed that $0.047 \%$ thymol in ethanol displayed the highest degree of anticaries activity against all the Streptococcal species tested. Incorporation of preservatives in mouthwashes may adversely affect their anticaries activity as indicated by the fact that the preserved mouthwash exhibited lower activity than the unpreserved mouthwash.

Conclusion: Anticaries activity is optimally achieved by using appropriate mouthwash combinations as this prevents both the initiation and progression of dental caries. The use of preservatives in mouthwash formulations should be done with caution as this may interfere with mouthwash activity.
\end{abstract}

Keywords: Mouthwash, Thymol, Anticaries activity, Bacterial isolates 


\section{INTRODUCTION}

There are relatively few infectious diseases of the upper alimentary canal but one common disease is dental caries which has been defined as a pathological process of destruction of tooth structure by microorganism [1]. Dental caries has also been defined as an ecological disease in which the diet, the host and the microbial flora interact over a period of time in such a way as to encourage demineralization of the tooth enamel with resultant caries formation [2]. Dental caries is still a major oral health problem in most industrialized countries, affecting $60-90 \%$ of school children and the vast majority of adults. It is also a most prevalent oral disease in several Asian and Latin American countries, but it appears to be less common and less severe in most African countries [3].

Two bacteria species have been implicated in caries formation, namely, Streptococci mutans and Lactobacilli. It has been clearly shown in many in-vivo and in-vitro studies that a process starting with the colonization of Streptococci mutans and continuing with the contribution of Lactobacilli in susceptible individuals, leads eventually to caries initiation and progression [4-7]. However, both S. mutans and Lactobacillus are acidogenic and aciduric, meaning that they produce acids which can dissolve the tooth substance - calcium phosphate in the form of hydroxyapatite crystals - and that they can survive and produce acids in a low $\mathrm{pH}$ environment. An acidogenic environment is crucial to maintain the haemostasis of these organisms in dental plaque and to initiate the demineralization of the enamel surface $[8,9]$. Compared to other oral flora, $S$. mutans and Lactobacillus are cariogenic and have enzymes with greater resistance to acids. One of such enzymes is dextran-sucrase, produced by $S$. mutans and which converts the sucrose of food to dextrin; the dextrin then combines with salivary proteins to create a sticky, colourless film (plaque) on tooth surfaces [10]. Plaque that is not removed from the teeth mineralizes into calculus (tartar). Plaque and calculus irritate the gums, resulting in gingivitis and ultimately, periodontitis.

The acids in plaque dissolve the enamel surface of the tooth and create cavities in the tooth. Cavities are usually painless until they grow very large inside the internal structures of the tooth (the dentin and the pulp at the core) and can cause death of the nerve and blood vessels in the tooth. If left untreated, tooth abscess and ultimately, loss of the tooth can result. Lactobacilli, on the other hand, produce lactic acid when exposed to high concentrations of sugar which, in turn, attacks the enamel by chelating calcium phosphate, thereby decalcifying it.

Depending on the extent of tooth destruction, various treatments can be used to restore teeth to proper form, function and aesthetics but there is no known method to regenerate large amounts of tooth structure. Instead, dental health organizations advocate preventive and prophylactic measures, such as regular oral hygiene and dietary modifications, to avoid dental caries [11]. One of the methods by which oral hygiene can be achieved is through the use of mouthwash. The roles of mouthwash in the prevention and treatment of dental caries cannot be overemphasized as a result of the pains and/or mouth-odour that have been linked to bacterial activity in the pulp of a carious tooth and the antibacterial activity of some mouthwashes.

There are many brands of mouthwash marketed in Nigeria, each with its own deodorant, antiseptic, disinfectant, analgesic and/or astringent property. In this study, an attempt was made at evaluating four major brands of mouthwash marketed in Nigeria for their anticaries property by subjecting some bacterial isolates from 30 dental-carious patients at a dental clinic in Ibadan, Nigeria to the antibacterial activity of the selected mouthwashes. 


\section{EXPERIMENTAL}

\section{Materials}

The microbial media used - Mueller-Hilton agar, mannitol salt agar, cetrimide agar, MacConkey agar, and blood agar - as well as nutrient broth, were all obtained from LAB $M$, Bury, UK while sterile normal saline was supplied by Dana Ashmina Ltd, Ibadan, Nigeria. A sample each of the four brands of mouthwash, labeled A - D, was purchased from a pharmacy outlet, Sagamu, Nigeria.

\section{Isolation and characterization of bacteria}

Extracted teeth were collected from 30 patients (comprising of equal number of male and female) presenting themselves for treatment of dental caries at Oyo State Government's owned Dental Clinic, Ibadan, Nigeria. Each tooth was collected separately in sterile normal saline and inoculated into sterile nutrient broth within $24 \mathrm{~h}$ using sterilized wire loop. The inoculated nutrient broth was incubated at $37{ }^{\circ} \mathrm{C}$ for $24 \mathrm{~h}$, samples of which were streaked on the surfaces of prepared sterile MacConkey agar, mannitol salt agar, blood agar and cetrimide agar media, respectively. The plates were then incubated at $37{ }^{\circ} \mathrm{C}$ for $24 \mathrm{~h}$ and observed for growth. Bacterial isolates were identified and characterized using conventional biochemical tests.including Gram stain, catalase, coagulase, oxidase, indole and citrate utilization.

\section{Evaluation of antibacterial activity of the mouthwashes}

The characterized bacterial isolates were aseptically transferred to sterile nutrient broth and incubated at $37^{\circ} \mathrm{C}$ for $24 \mathrm{~h} ; 0.1 \mathrm{ml}$ of the overnight growth culture was aseptically transferred into $9.9 \mathrm{ml}$ sterile normal saline to give a 1:100 dilution of the isolate. Out of this, $1 \mathrm{ml}$ was aseptically seeded in sterile MuellerHilton agar medium in a plate and allowed to set. Four wells were bored into each agar plate using a sterile $6 \mathrm{~mm}$ diameter cork borer and two drops of each mouthwash were dropped into separate wells using a sterile dropper. The plates were left on the bench for $1 \mathrm{~h}$ to allow for diffusion of the mouthwash samples into the agar medium. The procedure was carried out in duplicate. All the plates were then incubated at $37^{\circ} \mathrm{C}$ for $24 \mathrm{~h}$ and the zones of inhibition measured using an accurately calibrated transparent ruler. The mean diameter of the zones of inhibition was calculated.

Chlorhexidine solution (0.2 \%) was the positive control, while the negative control was a placebo (i.e., nothing was added to the well). Staphylococcus aureus ATCC 25923 and Escherichia coli ATCC 25922 were used as Gram positive and Gram negative control organisms, respectively.

\section{Statistical analysis}

The number of bacterial isolates showing zone of inhibition by each brand of mouthwash was statistically analyzed by subjecting them to Chi square test with Microsoft Excel Macro to determine if there were significant difference in their susceptibility patterns at $95 \%$ confidence level.

\section{RESULTS}

The compositions of each of the mouthwashes evaluated are shown in Table 1 while the bacteria isolated from 30 patients with dental caries are listed in Table 2. The susceptibility pattern of each bacterial isolate to each of the mouthwashes evaluated are presented in Table 3 as diameter of zone of inhibition (in $\mathrm{mm}$ ) or absence (-) of zone of inhibition.

\section{DISCUSSION}

Of the five different bacterial species associated with dental caries in this study, Staphylococcus aureus was the most prevalent, accounting for $30 \%$ of the total isolates. However, only Streptococcus has 
been implicated in the initiation and progression of dental caries [7]. This clearly indicates that organisms constituting oral flora and are associated with dental caries cut across continents and races as well as oral habits of humans.

Table 1: Composition of each mouthwash sample labeled A - D

\begin{tabular}{|c|c|}
\hline Mouthwash & Composition \\
\hline A & $\begin{array}{l}\text { Thymol B.P. }-0.047 \% \text { in } \\
\text { ethanol }(95 \%)\end{array}$ \\
\hline B & $\begin{array}{l}\text { Sodium Benzoate B. P. - } \\
2.0 \% \text { w } / v \text {, chlorhexidine } \\
\text { gluconate solution B. P. - } \\
0.12 \% \text { v } / v \text {, aqueous base }-\mathrm{q} \text {. } \\
\text { S., Color Brilliant Blue FCF and } \\
\text { tartrazine }\end{array}$ \\
\hline C & $\begin{array}{l}\text { Per } 10 \mathrm{ml} \text { : Alcohol (95\%)- } \\
7.0 \% \text {, cetylpyridinium chloride } \\
-5 \mathrm{mg} \text {, sodium benzoate - } \\
0.3 \% \mathrm{w} / \mathrm{v}\end{array}$ \\
\hline D & $\begin{array}{l}\text { Per } 20 \mathrm{ml} \text { : Thymol }-12.78 \mathrm{mg} \text {, } \\
\text { alcohol }(95 \%)-5.68 \mathrm{ml} \text {, } \\
\text { sodium benzoate and benzoic } \\
\text { acid. }\end{array}$ \\
\hline
\end{tabular}

Antimicrobial susceptibility profiles (Table 3 ) reveal that Mouthwash $A$ displayed activity against all isolated Streptococci species while the other mouthwashes did not. This suggests that Mouthwash A may play a vital role in the prevention of dental caries since Streptococcus has been implicated in the initiation of dental caries. Similarly, all isolated Pseudomonas aeruginosa showed sensitivity to Mouthwash A implying that sample A can also protect against invasion by the opportunistic pathogen especially in immunocompromised patients. However, while Mouthwash A may be effective at preventing initiation of dental caries and subsequent progression of the caries, Mouthwashes $B$ and $C$ may only be effective at curbing the progression of dental caries; on the other hand, the activity of Mouthwash D was poor at curbing caries initiation as it showed no activity against all the Streptococcal isolates.
Table 2: Distribution of bacterial isolates from extracted teeth by gender

\begin{tabular}{|c|c|c|c|c|c|c|}
\hline \multirow[b]{2}{*}{ 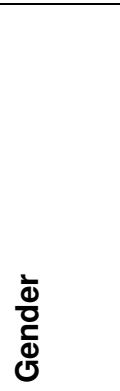 } & \multirow[b]{2}{*}{$\begin{array}{l}\frac{1}{\Phi} \\
\text { 을 } \\
\text { Z }\end{array}$} & \multicolumn{5}{|c|}{$\begin{array}{c}\text { Number of bacterial } \\
\text { isolates }\end{array}$} \\
\hline & & 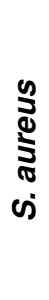 & 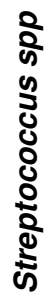 & $\begin{array}{l}\text { ठ̊ } \\
\text { نे }\end{array}$ & $\begin{array}{l}\frac{2}{0} \\
\text { के } \\
\frac{0}{5} \\
\frac{0}{5} \\
\frac{0}{1}\end{array}$ & 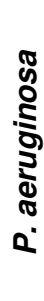 \\
\hline Male & 13 & 3 & 2 & 2 & 5 & 1 \\
\hline Female & 17 & 6 & 4 & 3 & 3 & 1 \\
\hline
\end{tabular}

However, chlorhexidine (0.2 \%) was active against all the bacterial isolates including the control but none of the mouthwashes exhibited activity against the control organisms. There was no significant difference in the susceptibility patterns of the bacterial isolates to which they were exposed.

The spectrum of antibacterial activity displayed by the mouthwashes may be linked with their active constituents. Mouthwashes $\mathrm{B}$ and $\mathrm{C}$ contain chlorhexidine gluconate (a biguanide) and cetylpyridinium chloride (a quaternary ammonium compound, QAC), respectively. The mechanism of action of chlorhexidine is membrane disruption, causing concentration-dependent growth inhibition and cell death [12]. Secondary interactions causing inhibition of proteolytic and glycosidic enzymes may also be significant [13]. However, the antimicrobial action of QACs involves perturbation of cytoplasmic and outer membrane lipid bilayers through association of the positively charged quaternary nitrogen with the polar head groups of acidic phospholipids [14].The hydrophobic tail subsequently interacts with the hydrophobic membrane core. Lethality occurs through generalized and progressive leakage of cytoplasmic materials [15]. On the other hand, Mouthwashes A and D contain 
Table 3: Antibacterial activity (zone of inhibition, $\mathrm{mm}$ ) of the mouthwashes against bacterial isolates from dental caries

\begin{tabular}{|c|c|c|c|c|c|}
\hline \multirow{2}{*}{$\begin{array}{l}\text { Tooth } \\
\text { no. }\end{array}$} & \multirow[b]{2}{*}{ Bacterial isolate } & \multicolumn{4}{|c|}{ Mouthwash } \\
\hline & & A & B & C & D \\
\hline 1 & Staphylococcus aureus & - & 6 & 7 & 2.5 \\
\hline 2 & Streptococcus $s p$ & 1.5 & - & - & - \\
\hline 3 & Streptococcus $s p$ & 1.6 & - & - & - \\
\hline 4 & Streptococcus $s p$ & 1.5 & 0.5 & - & - \\
\hline 5 & Staphylococcus aureus & 3.5 & 5.5 & 4.5 & - \\
\hline 6 & Streptococcus $s p$ & 1.5 & - & - & - \\
\hline 7 & Streptococcus $s p$ & 1.4 & - & - & - \\
\hline 8 & Staphylococcus aureus & 4.0 & 4.5 & 5.0 & - \\
\hline 9 & Escherichia coli & - & 19 & 6.0 & - \\
\hline 10 & Staphylococcus aureus & 2.5 & 6.5 & 5.5 & 1.8 \\
\hline 11 & Escherichia coli & - & 21.5 & 4.5 & - \\
\hline 12 & $P$. aeruginosa & 4.5 & 2.5 & - & - \\
\hline 13 & Klebsiella $s p$ & - & 14.5 & 13.5 & - \\
\hline 14 & Klebsiella sp & - & 17 & 7.5 & 5.5 \\
\hline 15 & Klebsiella sp & - & 19 & 14.5 & - \\
\hline 16 & Klebsiella sp & - & 12.5 & 12.5 & - \\
\hline 17 & Staphylococcus aureus & - & 7 & 4 & - \\
\hline 18 & Klebsiella $s p$ & - & 19.5 & 8.5 & - \\
\hline 19 & Klebsiella sp & - & 11 & 10.5 & - \\
\hline 20 & Staphylococcus aureus & - & 11 & 12.5 & - \\
\hline 21 & Escherichia coli & - & 12 & 10 & 9 \\
\hline 22 & Staphylococcus aureus & - & 17 & 10.5 & - \\
\hline 23 & Klebsiella $s p$ & - & 14 & 9 & 1.1 \\
\hline 24 & P.aeruginosa & 7.5 & 2.5 & 5.5 & 1.1 \\
\hline 25 & Escherichia coli & - & 14 & 11 & - \\
\hline 26 & Streptococcus $s p$ & 1.3 & - & - & - \\
\hline 27 & Staphylococcus aureus & - & 8 & 7 & 1.5 \\
\hline 28 & Staphylococcus aureus & - & 8.5 & 8 & 1.5 \\
\hline 29 & Escherichia coli & - & 12 & 11 & 6 \\
\hline 30 & Klebsiella $s p$ & - & 15.5 & 10.5 & - \\
\hline
\end{tabular}

- = no zone of inhibition

the same major constituents, namely, thymol (as deodorant) and alcohol/ethanol (as antibacterial agent). Ethanol only exhibits bactericidal activity or may not have any activity at all. This bactericidal activity may be through denaturation of both cellular and enzymic proteins, lytic action or interference with microbial cellular metabolism [16]. However, while Mouthwash A did not contain a preservative, Mouthwash D was preserved with sodium benzoate and benzoic acid. Although this is difficult to explain, it would appear that the preservative present in Mouthwash $D$ might have interfered with the antibacterial activity of its ethanol/alcohol content.

\section{CONCLUSION}

Isolation of bacteria other than Streptococcus species is an indication that the latter is not the only organism associated with the initiation and progression of dental caries. The varying spectra of antibacterial activities observed for the mouthwashes are indications that not all mouthwashes are suitable for the prevention and/or control of dental caries. This is contrary to the belief in some quarters that all mouthwashes possess essentially the same antibacterial activity. 


\section{REFERENCES}

1. MedlinePlus Encyclopedia [internet]. Dental Cavities. National Library of Medicine (US); [Updated 2010 March 23, cited 2010 April 15]. Available from http://www.n/m.nih.gov/medlinep/us/ency/articl e/001055.

2. International Obfuscated C Code Contest Report on Dental Caries. 1995

3. World Health Organization. The World Oral Health Report 2003; WHO/NMH/NPH/OPH/03.2

4. Nyvad B, Kilian M. Microflora associated with experimental root surface caries in humans. Infect Immun 1990; 58: 1628-1633

5. Marsh PD, Featherstone A, Mckee AS, Hallsworth AS, Robinson C. A microbiological study of early caries of approximal surfaces in schoolchildren. J Dent Res 1989; 68: 1151 1154

6. Tanzer JM. Dental caries is a transmissible infectious disease: The Keyes and Fitzgerald Revolution. J. Dent Res 1985; 74: (9) 15361541

7. Duchin S, Van Houte J. Relationship of Streptococcus mutans and Lactobacilli to incipient smooth surface dental caries in man. Arch Oral Biol 1978; 23: 779

8. Igarashi $K$, Hamada $Y$, Nishimaki H, Sakurai S, Kamiyama, K. The acidogenic potential of plaque from sound enamel, white spot lesions, and cavities in children. Pediatr Dent 1987; 9: 212-215

9. Sansone C, Van Houte J, Joshipura K, Kent $R$, Margolis HC. The association of mutans streptococci and non-mutans streptococci capable of acidogenesis at a low $\mathrm{pH}$ with dental caries on enamel and root surfaces.

J. Dent Res 1993; 72: 508-516

10. Amaechina OO. Three-Minute Herbal Treatment to Reduce Dental Caries with a Newbouldia laevis Based Extract. Am J Undergrad Res 2003; 2(2): 1-4.

11. Oral Health Topics [internet]: Cleaning your teeth and gums. Hosted on the American Dental Association website. [Page accessed March 30, 2010]. Available on http://www.ada.org/public/topics/cleaning.

12. Hugo WB, Longworth AR. The effect of chlorhexidine on the electrophoretic mobility, cytoplasmic constituents, dehydrogenase activity and cell walls of Escherichia coli and Staphylococcus aureus. J. Pharm. Pharmacol. 1966; 18: 569-578.

13. Hastings DC. Non-antibiotic plaque chemotherapy 2000, p 523-548 In: H. N. Newman and Wilson (ed) Dental plaque revisited: Oral biofilms in health and disease. Bioline press, Cardiff, United Kingdom.

14. Gilbert P, Al-Taae ANA. Antimicrobial activity of some alkyl-trimethyl ammonium Bromide. Lett. Appl. Microbiol., 1985; 1: 101-105.

15. Lambert, P. A. and Hammod, S. M. Potassium fluxes, first indication of membrane damage in microorganisms. Biochim. Biophys. Acta 1973; 54: 796-799

16. Lamikanra A. Essential Microbiology. Amkra Books, Ilupeju Estate, Lagos, Nigeria. 